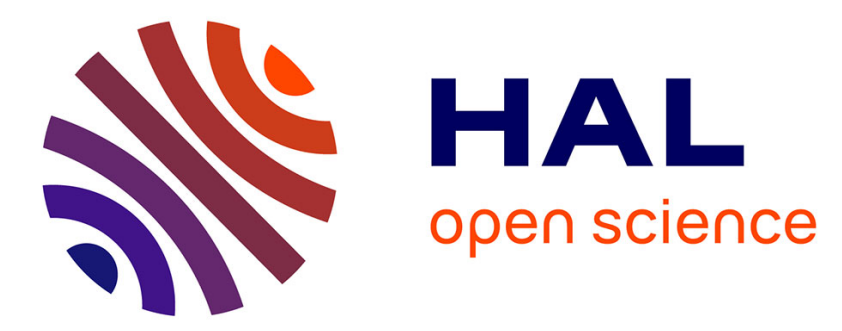

\title{
Cardiac magnetic resonance findings predict increased resource utilisation in elective coronary artery bypass surgery
}

Colin Berry, Lukas U Zimmerli, Tracey Steedman, John E Foster, Henry J Dargie, Geoffrey A Berg, Anna F Dominiczak, Christian Delles

\section{To cite this version:}

Colin Berry, Lukas U Zimmerli, Tracey Steedman, John E Foster, Henry J Dargie, et al.. Cardiac magnetic resonance findings predict increased resource utilisation in elective coronary artery bypass surgery. Clinical Science, 2007, 114 (6), pp.423-430. 10.1042/CS20070337 . hal-00479404

\section{HAL Id: hal-00479404 https://hal.science/hal-00479404}

Submitted on 30 Apr 2010

HAL is a multi-disciplinary open access archive for the deposit and dissemination of scientific research documents, whether they are published or not. The documents may come from teaching and research institutions in France or abroad, or from public or private research centers.
L'archive ouverte pluridisciplinaire HAL, est destinée au dépôt et à la diffusion de documents scientifiques de niveau recherche, publiés ou non, émanant des établissements d'enseignement et de recherche français ou étrangers, des laboratoires publics ou privés. 
Cardiac magnetic resonance findings predict increased resource utilisation in elective coronary artery bypass surgery

Authors: Colin Berry* ${ }^{\boldsymbol{1}^{1,2}}$, Lukas U. Zimmerli*1,2 , Tracey Steedman, ${ }^{1,2}$ John E. Foster, ${ }^{2}$ Henry J. Dargie, ${ }^{2}$ Geoffrey A. Berg, ${ }^{3}$ Anna F. Dominiczak, ${ }^{1,2}$ Christian Delles. ${ }^{1,2}$

* These authors contributed equally to this work.

${ }^{1}$ British Heart Foundation Glasgow Cardiovascular Research Centre, University of Glasgow, Glasgow.

${ }^{2}$ Glasgow Cardiac Magnetic Resonance Unit, Western Infirmary, Glasgow

${ }^{3}$ Department of Cardiac Surgery, Western Infirmary, Glasgow

Address for correspondence:

Dr Colin Berry, Cardiovascular Branch, National Heart Lung and Blood Institute, National Institutes of Health, 10 Center Drive, Bethesda, MD 208921538.

Email: berryc@mail.nih.gov Telephone: 301-402-1032

Word count: abstract: 246; manuscript (including references, legends and tables) 4423 


\begin{abstract}
Background: Morbidity following coronary artery bypass graft (CABG) surgery is difficult to predict and leads to increased healthcare costs. We hypothesised that preoperative cardiac magnetic resonance (CMR) findings would predict resource utilisation in elective CABG.
\end{abstract}

Methods: Over a 12-month period, elective CABG patients were invited to undergo CMR one day prior to CABG. Gadolinium-enhanced CMR was performed using a trueFISP inversion recovery sequence on 1.5 tesla scanner (Sonata, Siemens). Clinical data were prospectively collected. Admission costs were quantified based on standardised actual cost-per-day. Admission cost > median was defined as "increased".

Results: Of 458 elective CABG cases, 45 (10\%) underwent pre-operative CMR. Preoperative characteristics (mean (standard deviation) age 64 (9) years), mortality (1\%) and admission duration (median (interquartile range $7(6,8)$ days) were similar in patients who did or did not undergo CMR. In the CMR patients, eight (18\%) and 11 (24\%) patients had reduced left ventricular (LV) systolic function by CMR $(\mathrm{LVEF}<55 \%)$ and echocardiography, respectively. Late enhancement (LE) with gadolinium was detected in 17 (38\%) patients. The average cost-per-day was $\$ 2,723$. The median (range) admission cost was $\$ 19,059$ ( $\$ 10,891$ to $\$ 157,917$ ). CMR LVEF (odds ratio (OR) [95\% confidence interval (CI)] 0.93 [0.87 to 0.99]; $\mathrm{p}=0.03$ ) and stroke volume index (OR 1.07 (95\% CI 1.00 to 1.14); $\mathrm{p}=0.02)$ predicted increased admission cost. CMR LVEF $(\mathrm{p}=0.08)$ and EuroScore tended to predict actual admission cost $(\mathrm{p}=0.09)$, but $\mathrm{SV}$ by CMR $(\mathrm{p}=0.16)$ and LV function by echocardiography $(\mathrm{p}=0.95)$ did not. 
Discussion: In this exploratory investigation, preoperative CMR findings predicted admission duration and increased admission cost in elective CABG. The costeffectiveness of CMR for risk stratification in elective CABG merits prospective assessment.

Keywords: coronary artery disease; magnetic resonance imaging; coronary artery bypass surgery; resource utilisation

Licenced copy. Copying is not permitted, except with prior permission and as allowed by law. 


\section{Introduction}

Quality of care and resource utilisation have increasing importance in cardiovascular healthcare provision.[1] Coronary artery bypass grafting (CABG) is an effective but expensive treatment.[2-5] Despite low mortality rates following elective CABG,[2;6] post-operative morbidity is fairly common, leading to prolonged hospital admission and increased resource utilisation.[7-9]

Hospitalization costs are the leading cause for direct healthcare expenditure.[3;5;10] In cardiac surgery, predicting prolonged admission is notoriously difficult,[11;12] and risk assessment tools for morbidity [13] and mortality [12] place emphasis on unstable, highrisk characteristics. Consequently, prediction of admission duration and costs may be less reliable in lower-risk patients who represent the majority of CABG cases.[2]

Cardiac magnetic resonance (CMR) has high tissue contrast and spatial resolution, and has become the gold standard technique for assessment of cardiac structure and function.[14-16] Despite widespread availability, pre-operative CMR is usually not requested, and this is probably because of conventional reliance on echocardiography. However, compared with CMR, echocardiography is less accurate and provides no information on viability, and acoustic limitations are fairly common.[14]

Information about the utility of CMR for the prediction of in-hospital outcomes in elective (low risk) CABG is lacking. We hypothesised that CMR findings prior to CABG would correlate with post-operative morbidity and predict resource utilisation. Specifically, we investigated the following questions. First, could late enhancement (LE) with gadolinium be feasible as part of a routine assessment in low-risk patients prior to 
elective CABG. Second, which characteristics, including those obtained from CMR, correlate with in-hospital outcomes? Third, do CMR findings predict resource utilisation? To answer these questions, CMR was performed in a representative subset of patients undergoing elective CABG over a 12-month period.

\section{Methods}

Patients with multivessel coronary artery disease (CAD) undergoing elective CABG were invited to participate and gave informed consent. Patients undergoing CABG combined with valve surgery were not included. There were no other exclusion criteria.

One - two CMR studies took place per week over a twelve month period. Limitations in MR scanner availability due to other research activity precluded inclusion of more patients. MR data were not intended to guide clinical management. Clinical data were obtained from hospital electronic databases. Hospital costs were quantified based on actual standardised Scottish National Health Service (2005) costs per cardiac surgical bed day. This study was approved by the North Glasgow University Hospitals NHS Trust Ethics Committee.

\section{CMR image acquisition - pre-gadolinium contrast imaging}

CMR was performed with a 1.5 tesla scanner (Sonata, Siemens, Erlangen, Germany) one day prior to CABG according to previously reported methods.[17] Fast imaging at steady state free precession cines (TrueFISP by Siemens) were used throughout for all pregadolinium cines. The images were first acquired in a long axis plane (vertical long axis, horizontal long axis, and left ventricular (LV) outflow tract) followed by sequential short axis LV cine loops from the atrioventricular ring to the LV apex. 
Pre-gadolinium imaging parameters, which were standardised for all subjects, included:

Repetition time $3.2 \mathrm{~ms}$, echo time $1.6 \mathrm{~ms}$, flip angle $20^{\circ}$, field of view $276 \mathrm{~mm} \mathrm{x}$ $340 \mathrm{~mm}$, pixel dimensions $2.0 \mathrm{~mm}$ x $1.3 \mathrm{~mm}$. Eight millimetre imaging slices were used with a $2 \mathrm{~mm}$ interslice gap.

\section{CMR image analysis - pre-gadolinium}

LV images were analysed using dedicated software (Argus VA60C 2004, Siemens, Erlangen, Germany). Individual scans were coded by number and analysed in batches. Investigators were blinded to patient characteristics and in-hospital outcomes following CABG. LV volumes [LV end-diastolic volume (LVEDV) and LV end-systolic volume (LVESV)] were determined by manual planimetry of selected short axis images, as described previously.[17-19] Particular methodological points of note included the deliberate inclusion of trabeculations and papillary muscles in all analyses.[19] The most basal ventricular slice was identified visually and then cross-referenced with the horizontal long axis view before its inclusion in the final analysis to ensure this slice was indeed ventricular and not atrial.

Two observers (C.B.; L.Z.) evaluated LV dimensions and function. In a subset of 10 patients, the inter-observer correlations were: end-diastolic volume, $r=0.87, p=0.002$; end-systolic volume, $\mathrm{r}=0.86, \mathrm{p}=0.003$; $\mathrm{SV}, \mathrm{r}=0.83, \mathrm{p}=0.005$, and $\mathrm{LV}$ mass $\mathrm{r}=0.85$, $\mathrm{p}=0.004$

According to CMR, a reduced LVEF was defined as < 55\%.[20] LV dimensions were indexed to body surface area.[21] 


\section{Gadolinium contrast enhanced-CMR image acquisition}

All patients underwent dynamic gadolinium-enhanced CMR. Gadolinium imaging was performed by injection of gadolinium-diethylene triaminepentaacetic acid at a dose of 0.2 $\mathrm{mmol} / \mathrm{kg}$ followed 10 minutes later by short axis stack image acquisition with a gadolinium-sensitive inversion recovery technique [Siemens inversion recovery TurboFLASH (fast low angle shot)] and identical slice positions as the pre-gadolinium cines.[22] Standardised scan settings were used for CMR in all subjects:

Repetition time $11.6 \mathrm{~ms}$, echo time $4.3 \mathrm{~ms}$, flip angle $20^{\circ}$, pixel dimensions 2.2 x 1.3 x 8 $\mathrm{mm}$ / number of segments 23. Eight millimetre imaging slices were used with a $2 \mathrm{~mm}$ interslice gap. The TurboFLASH inversion time was optimised on an individual patient basis. Successful nulling of normal myocardium was deemed to have been achieved once the LV myocardium appeared black and homogenous. An inversion time between 240 and 280 ms was required to achieve this. Artefacts on the LE images were excluded by the acquisition of 'swapped phase' images through slice planes which appeared to demonstrate intramyocardial gadolinium enhancement. This technique involves the 'swapping' of the phase-encoding and frequency-encoding directions, as the phaseencoding direction is particularly prone to artefacts caused by cardiac or chest wall movement.

\section{Gadolinium contrast enhanced-CMR image analyses}

Our approach to LE analyses methods have been recently described in detail.[23] Briefly, $\mathrm{LE}$ was defined as an area of visually identified gadolinium enhancement with a mean signal intensity (SI) that was more than one standard deviation higher than the mean SI of an adjacent area of reference myocardium, which although nulled had a mean SI 
significantly above zero. LE volume was determined by planimetry of any areas of gadolinium enhancement meeting these criteria. LE mass was calculated by multiplying gadolinium enhancement volume by myocardial density $\left(1.05 \mathrm{~g} / \mathrm{cm}^{3}\right)$ and these data were used in the subsequent correlations and discussion as the absolute measured value of gadolinium enhancing tissue.

Regional LV hypoperfusion on first-pass was visually assessed and documented using a 16 segment model. A first-pass perfusion score (FPS) was determined according to the method of Baks et al.[24] Each segment was evaluated and scored as 1) normal enhancement 2) $<30 \%$ wall thickness subendocardial hypoenhancement or 3) $>30 \%$ hypoenhancement. Infarct size was defined as an area of LE. Persistent microvascular obstruction (PMO) was defined as an area of reduced signal intensity within an area of LE.[25-27] Infarct size and PMO were quantified on the 3D-volume by manual delineation of the enhanced and unenhanced myocardium with different contours (Argus software, Siemens, Germany) and expressed as a percentage of LV mass.[23;25;26] PMO was included in the infarct size quantification.

\section{Echocardiography}

Echocardiograms were performed by experienced technicians and reports were issued by cardiologists. Reduced LV systolic function was defined as a left ventricular ejection fraction 0.40 or a qualitative report of depressed LV systolic function (mild, moderate or severe), which is the standard reporting method in our service.[28] Echocardiograms were performed within 2 months of surgery. 


\section{Statistical analyses}

We hypothesised that subtle abnormalities in LV function detected by CMR would be associated with prolonged admission duration $>7$ days. With 22 subjects in each group (admission duration, normal vs. prolonged), a mean between group difference in LVEF of $10 \%$ (SD of $10 \%$ ), could be detected with $90 \%$ power assuming a Type I error of 0.05 .

The distribution of all continuous data were visually inspected on a Normal plot. Normality was confirmed or excluded using the Shapiro-Francia test. Mean (SD) values and medians (interquartile range) were calculated for normally and non-normally distributed data, respectively. Correlations between normally and non-normally distributed variables were tested by Pearson's or Spearman's rho tests, respectively. All tests were two-tailed.

Increased admission duration was taken to represent one week or more, consistent with the median duration of admission which was 7 days. For resource utilisation, the total admission cost was calculated by multiplying the average-cost-per day for cardiac surgery in the Western Infirmary (2005) by individualised length of stay. A currency exchange rate of $£ 1$ : $\$ 1.90$ was used to estimate costs in US dollars.

Predictors of admission cost and increased admission cost were assessed using simple and logistic regression models, including in the subset of patients with LE $(n=17)$. For the univariate models, the coefficient of variation (continuous data) and odds ratio (categorical data) for a given increment of the covariate are reported along with 95\% confidence intervals (CI) and the associated P-value. 
A significance level of $5 \%$ was used in all tests. No adjustment was made to $P$-values to account for multiple testing. All statistical analyses were performed using STATA version 7 (Statacorp, College Station, Tx).

\section{Results}

\section{All patients}

Four hundred and fifty eight elective CABG cases were performed in our center between April $7^{\text {th }}, 2004$ - April $19^{\text {th }}, 2005$. The characteristics of these patients are presented in Table 1. Previous myocardial infarction (MI) and percutaneous coronary intervention were more frequent in the CMR group, whereas operative risk tended to be higher in the non-CMR group. The number of grafts, admission duration, and mortality were similar.

\section{CMR patients}

Pre-operative gadolinium-enhanced CMR was performed in 45 elective CABG patients with on average, 1 to 2 MR studies per week according to scanner availability (Table 2). Eight (18\%) patients had reduced LVEF defined by CMR, whereas 11(24\%) patients had reduced LV systolic function according to echocardiography. Only 4(9\%) patients had reduced LV systolic function by both methods. LVEF was lower in men (mean (SD) 61 (10) \%) than in women (mean (SD) 73 (6) \%; $\mathrm{p}=0.002$ ). LE was detected in 17(38\%) patients. Six of these patients had evidence of PMO (mean (SD) 1.3 (0.6) \%), all of whom had a clinical history of MI.

\section{In-hospital outcomes}

A 73 year-old diabetic man died on the $3^{\text {rd }}$ post-operative day. He had a reduced preoperative LVEF (46\%) and evidence of LE (IS 26\%, PMO 2\%). 
The median (IQR) duration of admission was $7(6,8)$ days. The minimum and maximum admission durations were 4 to 58 days. Compared to CMR patients with a normal admission duration, patients with an increased admission duration ( $>7$ days) had a lower LVEF, a higher ESV index (Table 3a), and more post-operative complications (Table 3b). Admission duration correlated with $\operatorname{LVEF}(\mathrm{R}=-0.34 ; \mathrm{p}=0.02)$ and tended to correlate with the EuroScore $(\mathrm{R}=0.22 ; \mathrm{p}=0.08)$ and $\mathrm{ESV}$ index $(\mathrm{R}=0.28 ; \mathrm{p}=0.06)$. No other clinical or CMR findings correlated with admission duration.

CMR LVEF univariately predicted increased admission duration (OR (95\% confidence interval) 0.93 (0.87 to 0.99 ); $\mathrm{p}=0.03$ ), and tended to predict actual admission duration (coefficient of variation -0.21 ( -0.44 to $0.03 ; \mathrm{p}=0.08)$. When EuroScore data were added to this model, the prognostic value of CMR LVEF tended to be retained (OR 0.94 (95\% CI 0.98 to 1.005); $\mathrm{P}=0.069)$, whereas the EuroScore did not predict this event $(\mathrm{P}=0.12)$.

\section{Resource utilisation}

The average cost-per-day was $\$ 2,723$. The median (interquartile range) admission cost was $\$ 19,059$ (\$16,336, $\$ 21,782)$. The admission cost ranged widely from a minimum of $\$ 10,891$ to a maximum of $\$ 157,917$.

LVEF by CMR predicted increased admission cost ((OR $(95 \% \mathrm{CI})$ cost $>$ median value 0.93 (0.87 to 0.99); $\mathrm{p}=0.03$ ) and tended to predict actual admission cost (co-efficient of variation (95\%Cl): -565.65 (-1202.48 to 71.19$) ; \mathrm{p}=0.08)$. The EuroScore tended to predict actual admission cost $(\mathrm{p}=0.09)$, but SV by CMR $(\mathrm{p}=0.16)$ and LV function by echocardiography $(\mathrm{p}=0.95)$ did not. 


\section{Discussion}

In this exploratory investigation, we found that CMR findings correlated with admission duration, and predicted resource utilisation in elective CABG. To the best of our knowledge, this study is the first of its kind.

\section{Clinical relevance}

Our findings are interesting for several reasons. First, CMR took place one day prior to elective CABG. CMR was feasible (scan time $<45 \mathrm{~min}$ ) and uncomplicated. Second, despite the small sample size and low rate of post-operative complications, CMR findings, and in particular, LV function, correlated with admission duration. Notably, other than the EuroScore, no other variable correlated with admission duration. CMR LVEF retained its prognostic value, even when combined in a regression model with the EuroScore. Third, based on actual in-hospital costs, CMR predicted increased resource utilisation. Our observations raise the possibility that CMR could be useful for risk assessment in lower-risk stable patients referred for CABG, with potential economic benefits.[29]

Patients with prolonged admission had depressed cardiac function, as revealed by CMR. Furthermore, these patients experienced an increased frequency of post-operative cardiovascular complications, including atrial fibrillation, which likely contributed to their prolonged admission duration. Although CMR was performed in a subset of patients, the characteristics and in-hospital outcomes of these patients were broadly similar to those of all patients who underwent elective CABG during the study period. 
For CMR to be a useful risk prediction instrument, it should be performed earlier than was done in the present study. CMR might take place once the decision for CABG has been taken. Potentially, CMR could be performed with a view to triage of risk, which in turn could help plan for bed availability and therefore guide the operation date. Alternatively, CMR could be performed much earlier in the patient journey. As stress perfusion CMR can inform on the presence of regional ischemia, as well as left ventricular function, CMR could be used as the main method for cardiac imaging to help guide the decision regarding revascularisation, whilst also informing on surgical risk. Future prospective studies will be required to evaluate these different approaches.

\section{Current limitations for prediction of morbidity in low-risk CABG}

Unlike prediction of mortality,[30] prediction of non-fatal post-operative complications is notoriously difficult.[11;12] Well-validated risk prediction instruments for in-hospital mortality, such as the EuroScore,[30] may not reliably predict post-operative morbidity.[12] This is particularly the case in lower-risk stable patients who represent the greatest proportion of CABG cases. In the present study, the EuroScore weakly correlated with admission duration.

Prolonged intensive care bed occupancy leads to substantially increased costs, including indirect financial losses through blocked beds and reduced surgical activity. Uncertainty exists about which patients may experience prolonged admissions, and despite the availability of risk tools to predict prolonged length of stay,[13;31-34] they are not consistently used to guide management. One reason for the limited utility of current risk instruments is the strong weighting accorded to emergency surgery.[13] Importantly, the 
absolute number of post-operative complications is probably greatest in lower-risk patients, in whom risk-instruments will have least positive predictive value.

Our study suggests CMR may represent a sensitive method for pre-operative risk prediction. Indeed, the fact that no other traditional prognostic characteristics, including LV function by echocardiography,[12;13;33] predicted admission duration, raises the possibility that CMR may be a more sensitive risk predictor in elective CABG than existing methods. Echocardiography has a lower accuracy than CMR for the assessment of LV systolic function,[14;29] which may explain the lack of correlation of LV function by echocardiography with admission duration.

\section{CABG, resource utilisation, and potential utility of CMR for risk prediction}

Although morbidity and mortality rates in our patients were low, admission duration was greater than one week in over half the patients. Consequently, admission costs ranged widely. In the UK, the average cost-per-CABG in 2003 was $\$ 17,596$ (Scotland), and the national in-hospital costs for CABG were approximately $\$ 500$ million.[5] In 2003, expenditure in the United States for in-hospital care was $\$ 94.1$ billion, of which $\$ 60$ (64\%) billion was for CAD.[35] In 2005, 145,333 isolated CABGs were performed, and the mean post-procedure length of stay was 6.9 days.[3] Average CABG costs in selected US and Canadian hospitals (1997 - 2001) were $\$ 20,673$ and $\$ 10,373$, respectively $(\mathrm{P}<0.001) \cdot[4]$

In this context, the incremental unit cost of CMR compared with echocardiography (approximately $\$ 1000$ [14] is modest. Consequently, preoperative imaging and risk assessment by CMR has the potential to be a cost-effective strategy should CMR-based 
management lead to reductions in peri-operative complications. Importantly, CMR also provides quantitative information on reversible myocardial ischemia, viability, infarct size, and thoracic pathology, all of which may be useful in the evaluation and management of patients being considered for revascularization.

\section{Conclusions}

LV function measured by CMR prior to elective CABG correlates with admission duration and predicts increased resource utilisation. CMR may be a more sensitive tool for risk assessment than conventional approaches in this setting. Since preoperative cardiac imaging is mandatory, we suggest the modest additional cost of CMR, compared with echocardiography, may potentially be offset by reduced resource utilisation. Although exploratory in nature, our observations raise the possibility that CMR prior to elective CABG coupled with targeted risk-reduction measures could lead to reduced resource utilisation. This hypothesis is in-line with contemporary healthcare recommendations,[1] and merits prospective assessment.

\section{Acknowledgements}

This work was funded by the British Heart Foundation Chair and Programme Grant British Heart Foundation PG/02/128 and the Wellcome Trust Cardiovascular Functional Genomics Initiative 066780/2/012 to AFD. LUZ was supported by the Swiss National Science Foundation (PBBSB-105860)/Lichtenstein-Stiftung Basel. CD was supported by a personal fellowship from the Deutsche Forschungsgemeinschaft (DE 826/1-1). The sponsors had no role in study design, data collection, data analysis, data interpretation, or viewing of the report. The corresponding author has final responsibility for manuscript 
submission. We would like to thank Mrs Margaret Kinnaird, and Drs Tom Martin, Robin Weir, and Paddy Mark for guidance on CMR analyses. 


\section{References}

1. Gibbons RJ (2007) Leading the Elephant Out of the Corner: The Future of Health Care: Presidential Address at the American Heart Association 2006 Scientific Sessions. Circulation 115, 2221-30

2. Ferguson TB, Hammill BG, Peterson ED, DeLong ER, Grover FL (2002) A decade of change - Risk profiles and outcomes for isolated coronary artery bypass grafting procedures, 1990-1999: A report from the STS National Database Committee and the Duke Clinical Research Institute. Ann. Thorac. Surg. 73, 480-9

3. Rosamond W, Flegal K, Friday G et al (2007) Heart disease and stroke statistics 2007 update - A report from the American Heart Association Statistics Committee and Stroke Statistics Subcommittee. Circulation 115, E69-E171

4. Eisenberg MJ, Filion KB, Azoulay A, Brox AC, Haider S, Pilote L (2005) Outcomes and cost of coronary artery bypass graft surgery-in the United States and Canada. Arch. Int. Med. 165,1506-13

5. British Heart Foundation. Heart Statistics (2006) Treatment (pages 61-77). British Heart Foundation, London, UK

6. Pell JP, Walsh D, Norrie J et al (2001) Outcomes following coronary artery bypass grafting and percutaneous transluminal coronary angioplasty in the stent era: a 
prospective study of all 9890 consecutive patients operated on in Scotland over a two year period. Heart 85, 662-6

7. Lassnigg A, Hiesmayr MJ, Bauer P, Haisjackl M (2002) Effect of centre-, patientand procedure-related factors on intensive care resource utilisation after cardiac surgery. Intensive Care. Med. 28, 1453-61

8. Hein OV, Birnbaum J, Wernecke K, England M, Konertz W, Spies C (2006) Prolonged intensive care unit stay in cardiac surgery: Risk factors and long-termsurvival. Ann. Thorac. Surg. 81, 880-5

9. Higgins TL (1998) Quantifying risk and assessing outcome in cardiac surgery. J Cardiothorac. Vasc. Anesth. 12, 330-40

10. Berry C, Murdoch DR, MicMurray J (2001) Economics of chronic heart failure Eur. J. Heart. Fail. 3, 283-91

11. Tu JV, Mazer CD (1996) Can clinicians predict ICU length of stay following cardiac surgery? Can. J. Anaesth. 43, 789-94

12. Geissler HJ, Holzl P, Marohl S et al. (2000) Risk stratification in heart surgery: comparison of six score systems. Eur. J. Cardiothorac. Surg. 17, 400-5 
13. Tu JV, Mazer CD, Levinton C, Armstrong PW, Naylor CD (1994) A predictive index for length of stay in the intensive-care unit following cardiac-surgery Can. Med. Assoc. J 151, 177-85

14. Pennell DJ, Sechtem UP, Higgins CB et al. (2004) Clinical indications for cardiovascular magnetic resonance (CMR): Consensus Pane report. Eur. Heart. J. 25, $1940-65$

15. Schvartzman PR, Srichai MB, Grimm RA et al. (2003) Nonstress delayedenhancement magnetic resonance imaging of the myocardium predicts improvement of function after revascularization for chronic ischemic heart disease with left ventricular dysfunction. Am. Heart. J. 146, 535-41

16. Selvanayagam JB, Kardos A, Francis JM et al (2004) Value of delayedenhancement cardiovascular magnetic resonance imaging in predicting myocardial viability after surgical revascularization. Circulation 110, 1535-41

17. Zimmerli LU, Mark PB, Steedman T et al. (2007) Vascular function in patients with end-stage renal disease and/or coronary artery disease: a cardiac magnetic resonance imaging study. Kidney. Int. 71, 68-73

18. Lorenz CH, Walker ES, Morgan VL, Klein SS, Graham TP (1999) Normal human right and left ventricular mass, systolic function, and gender differences by cine magnetic resonance imaging. J. Cardiovasc. Magn. Reson. 1, 7-21 
19. Sievers B, Kirchberg S, Franken U, Puthenveettil BJ, Bakan A, Trappe HJ (2005) Visual estimation versus quantitative assessment of left ventricular ejection fraction: A comparison by cardiovascular magnetic resonance imaging. Am. Heart. J. 150, 737-42

20. Alfakih K, Plein S, Bloomer T, Jones T, Ridgway J, Sivananthan M (2003) Comparison of right ventricular volume measurements between axial and short axis orientation using steady-state free precession magnetic resonance imaging. J. Cardiovasc. Magn. Reson. 18, 25-32

21. Mosteller RD (1987) Simplified calculation of body-surface area. N. Engl. J. Med. 317,1098

22. Simonetti OP, Kim RJ, Fieno DS et al. (2001) An improved MR imaging technique for the visualization of myocardial infarction. Radiology 218, 215-23

23. Mark PB, Johnston N, Groenning BA et al. (2006) Redefinition of uremic cardiomyopathy by contrast-enhanced cardiac magnetic resonance imaging. Kidney Int. 69, 1839-45

24. Baks T, van Geuns RJ, Biagini E et al. (2005) Recovery of left ventricular function after primary angioplasty for acute myocardial infarction. Eur. Heart J. 26, 1070-7 
25. Hombach V, Grebe O, Merkle N et al (2005) Sequelae of acute myocardial infarction regarding cardiac structure and function and their prognostic significance as assessed by magnetic resonance imaging Eur Heart J 26, 549-57

26. Lund GK, Stork A, Saeed M et al. (2004) Acute myocardial infarction: Evaluation with first-pass enhancement and delayed enhancement MR imaging compared with (TI)-T-201 SPECT imaging. Radiology 232, 49-57

27. Fieno DS, Kim RJ, Chen EL, Lomasney JW, Klocke FJ, Judd RM (2000) Contrastenhanced magnetic resonance imaging of myocardium at risk - Distinction between reversible and irreversible injury throughout infarct healing. J. Am. Coll. Cardiol. 36, $1985-91$

28. Berry C, Norrie JN, Hogg K, Brett M, Stevenson K, McMurray JJV (2006) The prevalence, nature and importance of hematologic abnormalities in heart failure. Am. Heart J. 151, 1513-21

29. Bellenger NG, Burgess MI, Ray SG et al. (2000) Comparison of left ventricular ejection fraction and volumes in heart failure by echocardiography, radionuclide ventriculography and cardiovascular magnetic resonance - Are they interchangeable? Eur. Heart J. 21, 1387-96 
30. Roques F, Nashef SAM, Michel P et al. (1999) Risk factors and outcome in European cardiac surgery: analysis of the EuroSCORE multinational database of 19030 patients. Eur. J. Cardiothorac. Surg. 15, 816-22.

31. Higgins TL, McGee WT, Steingrub JS, Rapoport J, Lemeshow S, Teres D (2003) Early indicators of prolonged intensive care unit stay: Impact of illness severity, physician staffing, and pre-intensive care unit length of stay. Crit. Care Med. 2003 31, $45-51$

32. Nathanson B, Higgins TL, Teres D, Copes WS, Kramer A, Stark M (2005) An updated method to assess ICU clinical performance and resource utilization. Crit. Care Med. 33, A26

33. Mounsey JP, Griffith MJ, Heaviside DW, Brown AH, Reid DS (1995) Determinants of the length of stay in intensive-care and in-hospital after coronaryartery surgery. Br. Heart J. 73, 92-8.

34. Michalopoulos A, Tzelepis G, Pavlides G, Kriaras J, Dafni U, Geroulanos S (1996) Determinants of duration of ICU stay after coronary artery bypass graft surgery. Br. J. Anaesth. 77, 208-12.

35. American Heart Association. Heart Disease and Stroke Statistics: 2003 Update. 2002. Dallas, Texas, American Heart Association. 


\section{Figure legend}

Figure 1. Mean (SD) left ventricular ejection fraction (LVEF) by CMR was higher (66 (10) \%) in patients with an admission duration $\leq 7$ days than in patients with an admission prolonged $>7$ days (59 (10) \%; $\mathrm{p}=0.02$ ). The Shapiro-Francia test confirmed LVEF data were normally distributed ( $\mathrm{p}>0.05)$. 


\section{Table 1. Clinical characteristics of elective CABG patients according to pre-operative CMR status (yes / no).}

\begin{tabular}{|c|c|c|c|}
\hline \multirow{2}{*}{ Clinical characteristics } & Pre-operative CMR & \multicolumn{2}{|c|}{ No-preoperative CMR $\mathrm{P}$} \\
\hline & $(n=45)$ & $(n=413)$ & \\
\hline Mean (SD) age, years & $63(9)$ & $65(9)$ & 0.16 \\
\hline Mean body mass index (SD), $\mathrm{kg} / \mathrm{m}^{2}$ & $29(4)$ & $29(4)$ & 0.50 \\
\hline Male gender, n (\%) & $37(82)$ & $319(80)$ & 0.7 \\
\hline History of myocardial infarction, n (\%) & $24(53)$ & $164(40)$ & 0.08 \\
\hline \multicolumn{4}{|l|}{ Diabetes, n (\%) } \\
\hline Non-insulin treated & $3(7)$ & $21(5)$ & 0.64 \\
\hline Insulin-treated & $9(20)$ & $64(15)$ & \\
\hline Hypertension, n (\%) & $31(69)$ & $266(64)$ & 0.55 \\
\hline Chronic lung disease, n (\%) & $2(4)$ & $47(11)$ & 0.15 \\
\hline Peripheral vascular disease, n (\%) & $1(2)$ & $39(9)$ & 0.10 \\
\hline History of PCI, n (\%) & $5(11)$ & $11(3)$ & 0.003 \\
\hline $\begin{array}{l}\text { Median (interquartile range) serum } \\
\text { creatinine, } \mu \mathrm{mol} / \mathrm{L}\end{array}$ & $102(95,113)$ & $102(93,116)$ & 0.88 \\
\hline $\begin{array}{l}\text { Angina grade, Canadian Cardiovascular } \\
\text { Class } 0 \text { / } 1 \text { / } 2 \text { / } 3 \text { / 4; n (\%) }\end{array}$ & $\begin{array}{l}1(2) / 9(20) / 20(44) / \\
13(29) / 2(4)\end{array}$ & $\begin{array}{l}20(5) / 52(13) / 176(43) / \\
128(31) / 37(9)\end{array}$ & 0.50 \\
\hline $\begin{array}{l}\text { New York Heart Association functional } \\
\text { class I / II / III, n (\%) }\end{array}$ & $14(31) / 22(49) / 9(20)$ & $\begin{array}{l}95(23) / 192(46) / 113 \\
(27) / 13(3)\end{array}$ & 0.33 \\
\hline \multicolumn{4}{|l|}{ Number of coronary artery grafts (n, \%) } \\
\hline $1-2 / 3 / 4-5$ & $15(33) / 25(56) / 5(11)$ & $88(21) / 268(65) / 57(14)$ & 0.2 \\
\hline \multicolumn{4}{|l|}{ Mean (SD) } \\
\hline EuroScore, \% & $2.5(1.6)$ & $3.2(2.3)$ & 0.03 \\
\hline Parsonnet risk, \% & $5(6)$ & $6(7)$ & 0.11 \\
\hline \multicolumn{4}{|l|}{ Drug therapy } \\
\hline Aspirin & $37(82 \%)$ & $362(88)$ & 0.30 \\
\hline Beta-blocker & $39(87 \%)$ & $334(81)$ & 0.34 \\
\hline ACE inhibitor & $25(44 \%)$ & $223(54)$ & 0.84 \\
\hline
\end{tabular}


Table 2. Dynamic gadolinium contrast enhanced cardiac magnetic resonance findings.

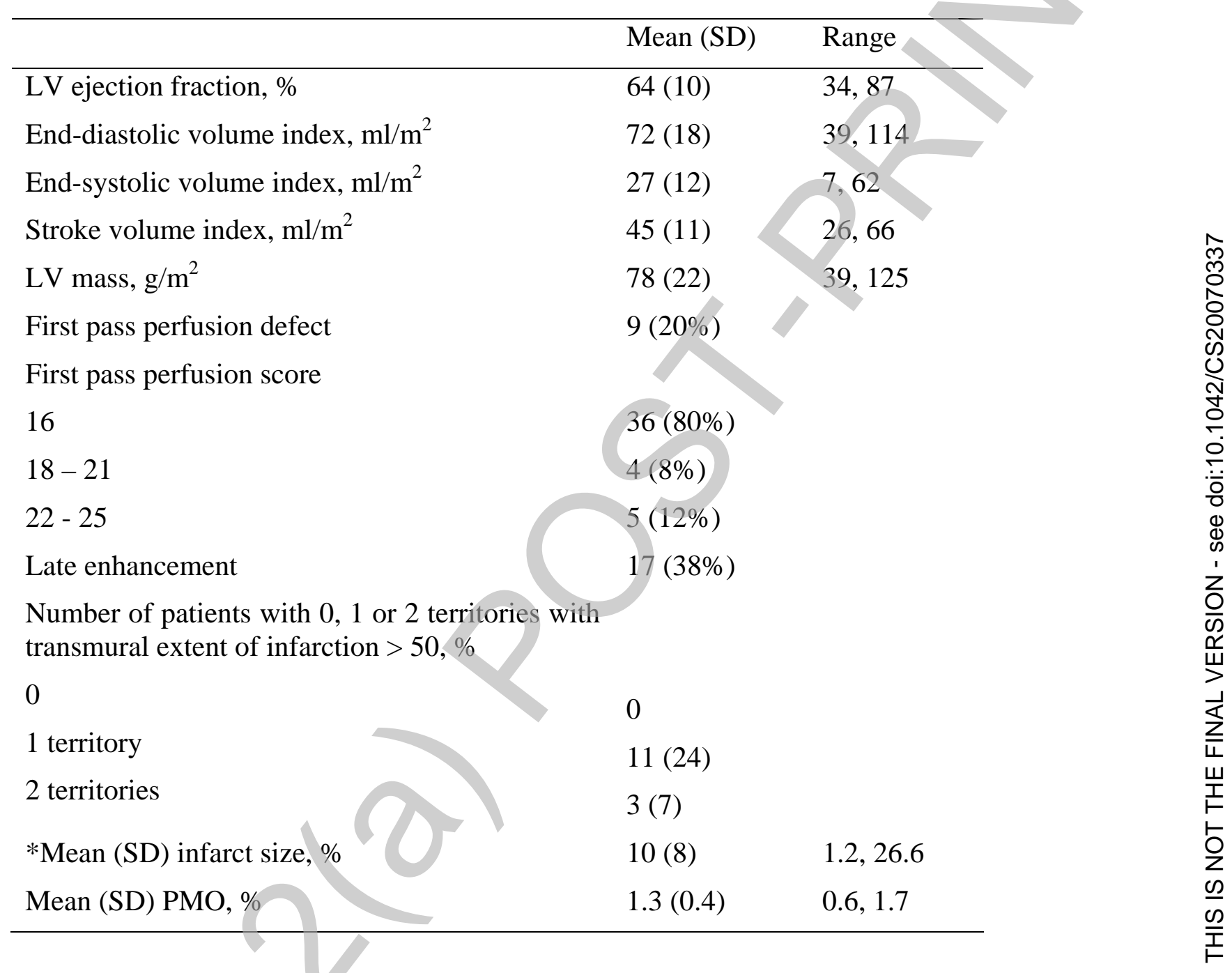

*LE was present in 17 patients, in whom 6 had evidence of persistent microvascular obstruction (PMO). Patients with a clinical history of MI had greater LE (11(8)\%) compared to patients without a history of MI (3.9(3.8)\%); $\mathrm{p}=0.04)$. 


\section{Table 3a. Preoperative characteristics in CMR patients according to admission duration $\leq$ or $>7$ days.}

Admission duration $\leq$ Admission duration $>\quad \mathrm{P}$

7 days $(n=29 ; 64 \%) \quad 7$ days $(n=16 ; 36 \%)$

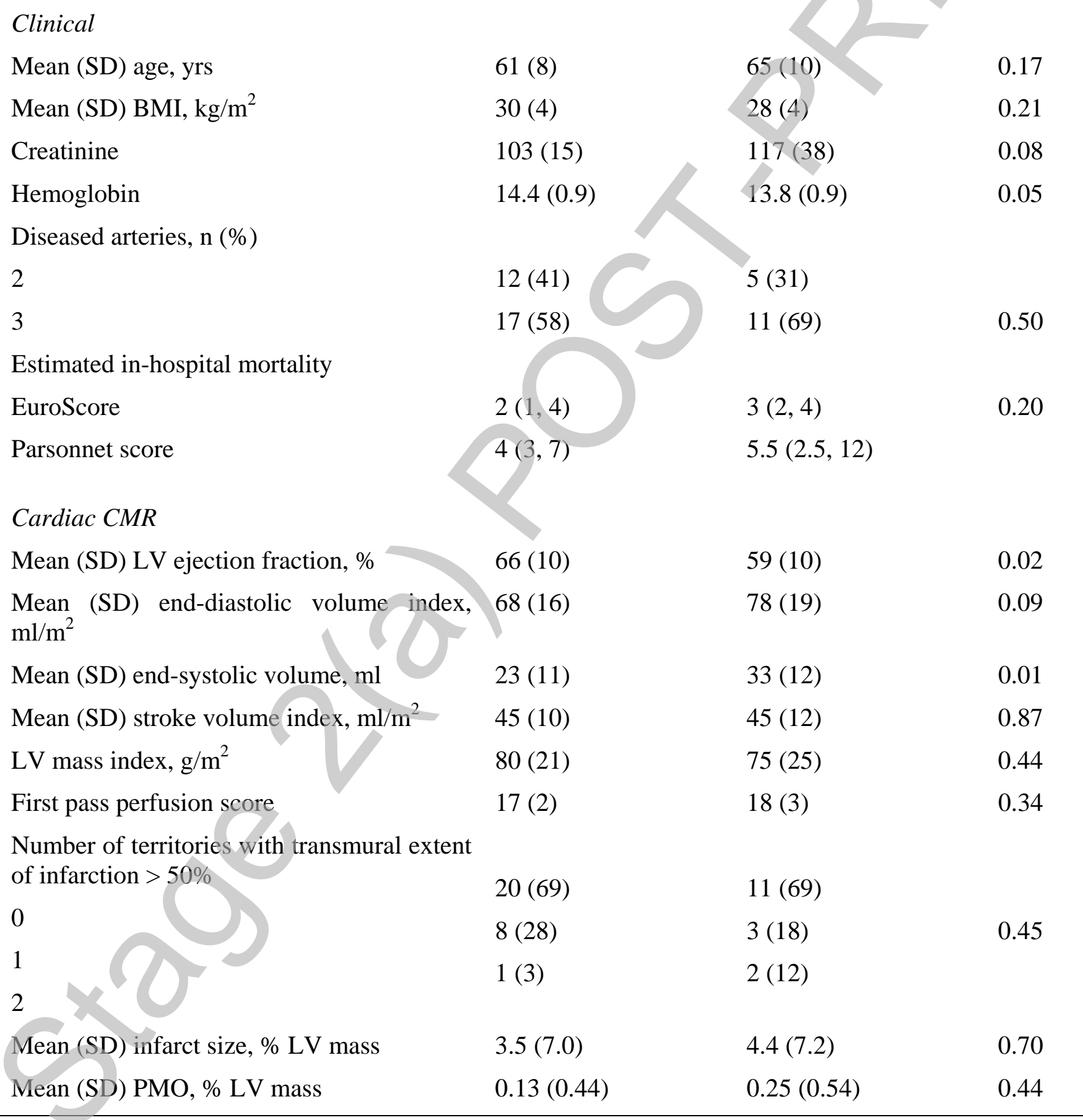




\section{Table 3b. Post-operative complications in CMR patients according to} admission duration $\leq$ or $>7$ days.

\begin{tabular}{llll}
\hline & $\begin{array}{l}\text { Admission duration } \leq \\
7 \text { days (n=29; 64\%) }\end{array}$ & $\begin{array}{l}\text { Admission duration }>7 \\
\text { days }(\mathrm{n}=16 ; 36 \%)\end{array}$ & $\mathrm{P}$ \\
\hline $\begin{array}{l}\text { *Major adverse cardiac and } \\
\text { cerebrovascular events }\end{array}$ & $1(3)$ & $1(6)$ & 0.66 \\
$\begin{array}{l}\text { Atrial flutter/fibrillation } \\
{ }^{\dagger} \text { Infection }\end{array}$ & $4(14)$ & $10(62)$ & 0.001 \\
Blood product transfusion & $8(28)$ & $1(6)$ & 0.66 \\
\hline
\end{tabular}

* One patient had a stroke and one other patient died. Infection was recorded if there was septicemia, or involvement of the leg, sternum, or mediastinum. 
Figure 1. Ejection fraction measured by pre-operative cardiac magnetic resonance and admission duration.

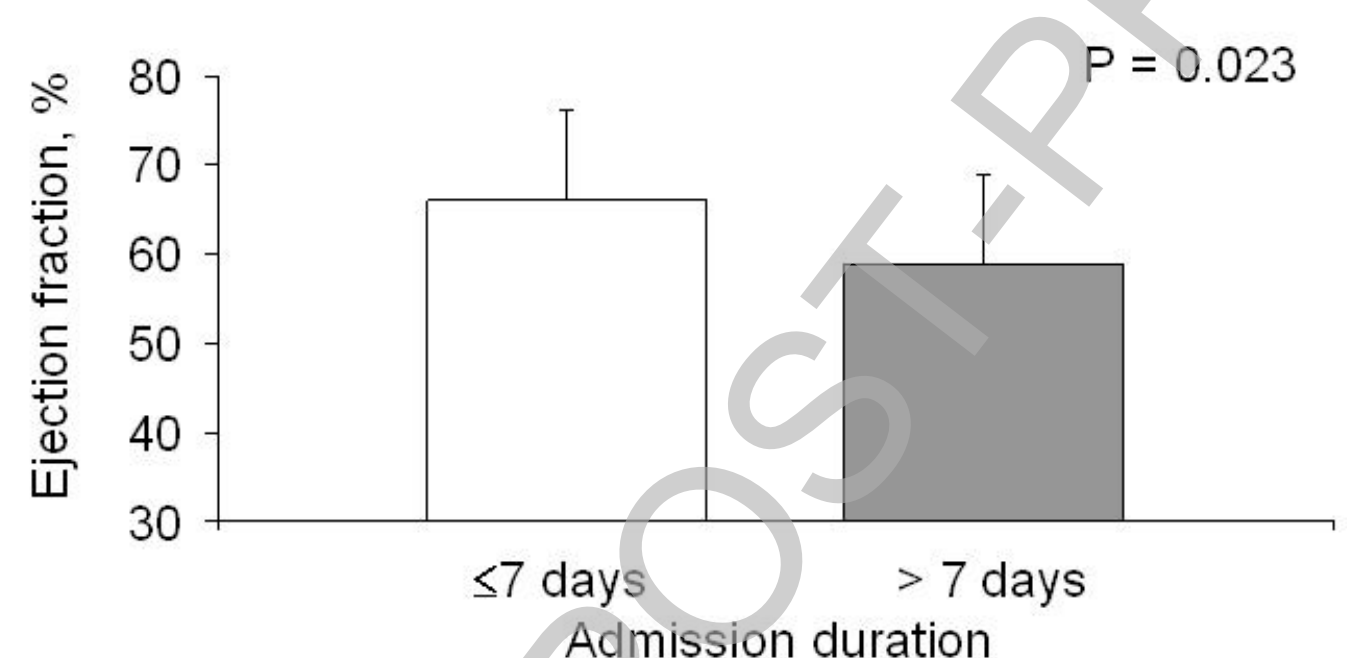

